\title{
SABERES DOCENTES E CULTURAS ESCOLARES NA PESQUISA COMO PRINCÍPIO EDUCATIVO DA EDUCAÇÃO DE JOVENS E ADULTOS DE FLORIANÓPOLIS (SC)
}

\section{Teachers' knowledge and school cultures in the research as educational principle of youth and adults education in Florianópolis (SC)}

\author{
Claudio Roberto Antunes Scherer Júnior ${ }^{1}$
}

RESUMO: Este trabalho busca compreender aspectos da ação docente presente na Pesquisa como Princípio Educativo (PPE) da Educação de Jovens e Adultos (EJA) da cidade de Florianópolis (SC). Toma como fonte entrevista com um professor que atuou na EJA em 2016. Essa fonte foi analisada tendo como categorias de análise o conceito de saberes docentes conforme apresentado por Tardif $(2000 ; 2010)$ e também foi utilizado o conceito de cultura escolar, cunhado por Julia (2001) e por Viñao Frago (2006). Esses conceitos foram as lentes pelas quais se pretendeu compreender e analisar a ação docente na EJA de Florianópolis. As primeiras conclusões indicam que as especificidades culturais, ou seja, o conjunto de normas, condutas, práticas e espaços ali encontrados, possibilitam um tipo de formação mediada pela lida cotidiana com situações e condicionantes inerentes ao ambiente de trabalho da EJA via PPE. Tal singularidade, entendida como possibilitadora de situações de formação, incita e induz saberes docentes ligados à prática dos professores nesse contexto específico.

Palavras-chave: Saberes Docentes. Cultura Escolar. Educação de Jovens e Adultos de Florianópolis. Pesquisa como Princípio Educativo.

\begin{abstract}
This work seeks to understand aspects of the teaching activity present in the Research as Educational Principle (Pesquisa como Princípio Educativo - PPE) of the Education of Young and Adults (Educação de Jovens e Adultos - EJA) in the city of Florianópolis (SC). It takes as an source an interview with a teacher who worked at the EJA in 2016. This source was analyzed having as categories of analysis the concept of teacher knowledge as presented by Tardif $(2000 ; 2010)$ and also used the concept of school culture developed by Julia (2001) and by Viñao Frago (2006). These concepts were the lens through which it was intended to understand and analyze the teaching activity in the EJA of Florianópolis. The first conclusions indicate that cultural specificities, that is, the set of norms, behaviors, practices and spaces found there, allow a type of training mediated by the daily deal

\footnotetext{
1 Mestre em Educação, Universidade Federal de Santa Catarina - UFSC. Apoio: UNIEDU/FUMDES/SC.
} 
with situations and conditions inherent to the work environment of the EJA via PPE. This singularity, understood as an enabler of training situations, incites and induces teacher knowledge linked to the practice of teachers in this specific context.

Keywords: Teaching knowledge. School Culture. Youth and Adult Education in Florianópolis. Research as an Educational Principle.

\section{INTRODUÇÃO}

A Educação de Jovens e Adultos (EJA) da cidade de Florianópolis funciona tendo a Pesquisa como Princípio Educativo (PPE). Isso significa uma série de mudanças teóricas, metodológicas e culturais daquilo que se convencionou como sendo um ambiente de ensino e, principalmente, daquilo que se pensa sobre um professor $^{2}$ em sala de aula.

Nesse ambiente de ensino os estudantes são estimulados a produzir pesquisas diretamente ligadas aos seus interesses pessoais, inexistindo separação de conteúdo por disciplinas ou áreas científicas e os professores atuam em grupo, muitas vezes, todos dentro da sala de aula ao mesmo tempo. Os professores, além de ensinarem, passam a ser orientadores dessas pesquisas.

Para a EJA via PPE funcionar é necessário uma série de mudanças na ação docente, ou seja, a prática desse professor, inserida nesse contexto específico da EJA de Florianópolis se difere da exercida em outras escolas. Nesse contexto, que desestimula completamente o "aulismo" ${ }^{3}$, o professor se depara com situações e condicionantes, talvez, nunca antes encontradas em sua vida. É nesse momento de incertezas e dúvidas que soluções, estratégias e saberes são acionados e/ou desenvolvidos.

Neste trabalho a intenção foi dar alguns passos no intuito de compreender, a partir do ambiente de ensino específico da EJA de Florianópolis, algumas nuances das mudanças ocasionadas na prática de ensino dos professores que ensejam o acionamento/desenvolvimento de saberes docentes na EJA. O pressuposto é de

\footnotetext{
${ }^{2}$ Ao longo do texto é utilizada a denominação professor e professores, no masculino, porém, trata-se de professores e professoras, homens e mulheres.

${ }^{3}$ Para Oliveira (2004, p. 32), o aulismo se refere "a ideia de que o professor entra e fala para as paredes alguma coisa, vai embora e acabou o compromisso." Oliveira (2004) foi um dos criadores da proposta com pesquisas desenvolvida na EJA de Florianópolis.
} 
que a proposta com pesquisas construa uma cultura escolar peculiar, com suas regras e normas próprias, com diferentes formas de ser/estar professor, com currículo e conteúdos específicos, e, que esse ambiente de ensino diferenciado possibilita a produção de saberes docentes inseridos nas diversas formas de realizar o trabalho dos professores.

Para este empreendimento, utilizarei os trabalhos de Tardif $(2000 ; 2010)$ sobre saberes docentes, os textos de Julia (2001) e Viñao Frago (2006) sobre cultura escolar. Para realizar essa análise é utilizada como fonte uma entrevista concedida por um professor de Espanhol que atuou na EJA em 2016. É a partir dessa fonte oral que se pretendeu compreender alguns aspectos da ação docente presente na PPE da EJA de Florianópolis.

Produzir fontes com base na oralidade pode acarretar uma série de dúvidas e perguntas. Todavia, Portelli (1996; 1997a; 1997b) aponta algumas luzes interessantes sobre esse tipo de fonte. Umas das questões, que apesar de há certo tempo superada, é com relação à subjetividade, como controlá-la, como lidar com ela? Portelli (1996, p. 62) afirma que "se formos capazes, a subjetividade se revelará mais do que uma interferência; será a maior riqueza, a maior contribuição cognitiva que chega a nós das memórias e das fontes orais." Essa percepção sobre a subjetividade da fala do entrevistado, faz com que seja possível pensar que numa entrevista, assim como em qualquer outro tipo de fonte, as subjetividades podem nos ajudar mais do que aquilo que se mostra, aparentemente, objetivo.

Este texto emerge de uma pesquisa de mestrado mais ampla ${ }^{4}$, aqui apenas o relato de um professor foi utilizado. A partir de sua fala é possível enfatizar momentos e situações que corroborarão com a proposta deste trabalho. Fazendo alusão à afirmação de Portelli (1997b, p. 25) sobre outra situação, porém, com o mesmo intuito, a de que esta pesquisa não busca "estudar" os docentes da EJA, mas antes, "aprender" algo a seu respeito.

A seguir, o intuito é apresentar um pouco da cultura escolar da EJA de Florianópolis com a especificidade gerada a partir da PPE. Após isso, a intenção é analisar alguns aspectos da formação de saberes docentes possibilitados pelas situações e condicionantes enfrentadas no cotidiano das interações na EJA.

\footnotetext{
${ }^{4}$ Cf. "AUTOR". Saberes Docentes na Educação de Jovens e Adultos em Florianópolis (SC). 2017. Dissertação (Mestrado em Educação). Universidade Federal de Santa Catarina. Florianópolis.
} 


\section{A CULTURA ESCOLAR DA EJA DE FLORIANÓPOLIS}

Cultura escolar, aqui entendida, se refere "a um conjunto de normas que definem conhecimentos a ensinar e condutas a inculcar, e um conjunto de práticas que permitem a transmissão desses conhecimentos e a incorporação desses comportamentos; normas e práticas coordenadas a finalidades que podem variar segundo as épocas." (JULIA, 2001, p. 10). Viñao Frago (2000, p. 2 e 3. Apud: FARIA FILHO, 2004, p. 148) aprofunda mais a explicação sobre o que vem a ser a cultura escolar:

Concepto de cultura escolar como un conjunto de teorias, ideas, princípios, normas, pautas, rituales, inercias, hábitos y práticas formas de hacer y pensar, mentalidades y comportamientos sedimentadas a lo largo del tiempo en forma de tradiciones, regularidades y reglas de juego no puestas en entredicho y que proporcionan estrategias para interactuar y para llevar a cabo, sobre todo en el aula, las tareas cotidianas que de cada uno se esperan, así como hacer frente a las exigencias y limitaciones que dichas tareas inplican o conllevan.

A EJA de Florianópolis, devido a Pesquisa como Princípio Educativo (PPE), apresenta uma cultura escolar com peculiaridades, ou seja, possui algumas práticas, hábitos e rituais que modificam a percepção naturalizada daquilo que acontece num ambiente de ensino, principalmente, em relação à ação docente.

A base do currículo da EJA são as pesquisas, os estudantes realizam pesquisas sobre interesses pessoais, sobre aquilo que querem pesquisar. Essa parece ser uma das primeiras e principais peculiaridades, que acarreta toda uma série de modificações nas normas e práticas encontradas na EJA de Florianópolis.

A entrevista com 0 professor Pablo ${ }^{5}$ apresenta alguns aspectos dessas mudanças e nos aponta outras significantes diferenças desse trabalho:

Ficamos mais tempo em grupo em cima de uma pesquisa só, [...] costumamos conversar bastante sobre as pesquisas, principalmente durante as aulas em que a gente trabalha pesquisas e nas orientações individuais com o grupo.

Nós somos oito professores, [...] outra atividade que fazemos são as oficinas, que é para ampliar algum conteúdo de uma pesquisa [...] A gente gosta de fazer oficinas de produção escrita [...] E, além disso,

\footnotetext{
${ }^{5} \mathrm{O}$ nome do entrevistado foi substituído por pseudônimo escolhido pelo próprio professor.
} 
tem o uso do caderno diário, que procuramos pedir para eles escreverem. (Prof. Pablo, entrevista, 2016, p. 3).

Nesse relato é possível identificar algumas das estratégias, práticas e rituais da lógica da ação docente na EJA e também perceber que o professor Pablo sempre se refere ao grupo de docentes na primeira pessoa do plural (nós), nunca no singular (eu), pois todos juntos são os responsáveis por tudo, nada é feito ou decidido sozinho. A pesquisa é central nas atividades e as orientações podem acontecer com mais de um professor ao mesmo tempo, o que significa a atenção de dois ou mais professores a um mesmo grupo de pesquisa, que no geral, comporta cerca de três alunos. Essas orientações se constituem em conversas sobre os temas escolhidos e prováveis modos de prosseguir com a investigação.

Além das pesquisas que cada aluno realiza com a orientação dos professores, outro aspecto do trabalho na EJA, relatado pelo referido professor, diz respeito às oficinas. As oficinas servem para aprofundar determinados aspectos de uma pesquisa, uma forma de aproveitar assuntos extraídos das próprias pesquisas e podem resultar numa produção escrita. Os cadernos de diário, também citado pelo professor Pablo, constituem-se em uma ferramenta de escrita sobre a vida dos estudantes, nele são feitas perguntas, relatos de situações reais ou fictícias que geram a resposta de algum professor, que tem a obrigação de estimular essa forma de conversa escrita. Além do já citado, o professor Pablo também comentou sobre a apresentação de filmes, às vezes nas sextas-feiras, como "uma maneira de levar um conteúdo de uma forma interessante para eles." (Prof. Pablo, entrevista, 2016, p. 3).

O professor entrevistado citou um momento fundamental para os trabalhos na EJA, a realização de formações: centralizadas e descentralizadas. As formações centralizadas acontecem num encontro em que todos os professores e coordenadores dos núcleos de $\mathrm{EJA}^{6}$ se reúnem para uma formação sobre determinados assuntos pertinentes aos seus trabalhos na escola.

As formações descentralizadas, mais conhecidas como reuniões de planejamento, acontecem entre os professores de um mesmo núcleo de EJA. Essas reuniões aconteciam as segundas e quartas-feiras no período da tarde. "Nessa reunião fazemos nossa programação da semana, nem sempre dá para fazer da semana inteira, mas a gente procura fazer até a quarta-feira, que é o dia da próxima

\footnotetext{
${ }^{6}$ No ano de 2016, Florianópolis contava com nove Núcleos de EJA. Informação obtida do Departamento de Educação de Jovens e Adultos (DEJA).
} 
reunião." (Prof. Pablo, entrevista, 2016, p. 2). Nesses encontros os professores junto do coordenador do núcleo falam do andamento das pesquisas, sobre os caminhos e prazos para a apresentação final, conversam sobre os estudantes, sobre algum problema de indisciplina e qualquer outra situação em que caiba um posicionamento de todos os professores. Nela também são decididas outras atividades: as oficinas, os filmes, além de passeios e outras atividades pedagógicas. Todos os professores participam dessas formações e podem opinar e levantar questões.

Existem algumas situações bem específicas na EJA de Florianópolis que merecem destaque e que colaboram para a percepção de uma cultura escolar peculiar. Nesse sentido a fala do professor Pablo é elucidativa:

Na EJA [...] nossa relação com os alunos é muito mais próxima do que a do 'ensino regular', então, eu consigo trocar essas ideias com eles muito mais das $18 \mathrm{~h}$ às $19 \mathrm{~h}$ e durante o intervalo em que a gente janta junto, também às vezes eu procuro ficar no dia da Educação Física. Gosto de agarrar no futebol com eles, isso traz uma proximidade muito maior e eu tenho muito acesso para conversar com eles. (Prof. Pablo, entrevista, 2016, p. 4).

O professor Pablo aponta momentos específicos de trabalho encontrado na EJA. O principal destaque é em relação à proximidade com os alunos, que não acontece apenas nos momentos de sala de aula. É possível notar que o professor entrevistado dá ênfase para momentos e situações específicas, que geram resultados positivos nessa relação mais próxima com os estudantes. O horário das aulas na EJA é das 19 às 22 horas. O momento entre as 18 e 19 horas, relatado pelo professor Pablo, é para organizar as ações daquela noite, para dividir tarefas entre os professores, para responder os cadernos diários e não especificamente para conversas com os estudantes, mas, essas conversas aconteciam e foram indicadas como sendo situações de destaque na relação com os discentes.

Uma situação, presente na fala do professor Pablo, que é inerente ao trabalho docente na EJA, é o fato de os professores, no intervalo, poderem jantar com os estudantes, comendo as mesmas comidas servidas na escola, nas mesmas mesas. Esses momentos de alimentação proporcionam uma interação única, uma partilha de um momento simples, porém, muito significativo na construção e manutenção de vínculos e laços afetivos.

O último destaque nessa fala do professor é com relação ao momento da "Educação Física”, em que alunos e professores participam das atividades de forma 
conjunta, fazendo desse momento, não apenas uma relação de um professor, no caso o de Educação Física, mas de todos os professores do Núcleo. Isso porque os dias reservados para a prática desportiva contam com a participação de todos os docentes, que interagem com os estudantes, participando diretamente $e$ compartilhando momentos de pura interação.

Essas interações específicas corroboram para a manutenção de uma situação relacional mais próxima. Essa proximidade gera um elo de amizade e respeito entre professores e alunos, facilitando o dia-a-dia nos núcleos e a manutenção das rotinas com as pesquisas e demais atividades. Lógico, como nos adverte Viñao Frago (2006, p. 80): "Cada estabelecimiento docente tiene, más o menos acentuada, su propria cultura, unas características peculiares. No hay dos escuelas, colegios, institutos, universidades o facultades exactamente iguales, aunque puedan estabelecerse similitudes entre ellas." Isso não é diferente com relação aos núcleos da EJA. Algumas práticas divergem entre os núcleos, e muitas vezes nem mesmo existem. As observações de campo apontam esse fato. Porém, essa relação de maior proximidade é uma situação que pode ser encontrada em todos os núcleos, muitas vezes, as situações que ocasionam essa proximidade podem variar, mas ela sempre acaba acontecendo, de um modo ou de outro, às vezes mais intensa, às vezes menos.

Seria possível citar outras situações que podem ser apontadas como específicas da EJA de Florianópolis no que concerne a sua cultura escolar, como por exemplo, a sala de aula da EJA, a interação de vários professores em sala ao mesmo tempo, a quase inexistente situação de "dar aula", os passeios pedagógicos, entre outras. Mas para a construção deste texto, os apontamentos feitos até aqui, servem para mostrar um pouco dessas especificidades encontradas na EJA e auxiliam na continuação da compreensão das possibilidades de ação docente inerentes a esse contexto de ensino.

\section{SABERES DOCENTES NA EJA DE FLORIANÓPOLIS}

O que é um saber? Segundo Tardif (2010, p. 193) "Na verdade, ninguém é capaz de produzir uma definição do saber que satisfaça todo o mundo, pois ninguém 
sabe cientificamente, nem com toda a certeza o que é um saber." Tardif (2010, p. 36) apresenta alguns direcionamentos para pensar em saberes docentes: "Pode-se definir o saber docente como um saber plural, formado pelo amálgama, mais ou menos coerente, de saberes disciplinares, curriculares e experienciais." É nesse amálgama que se situa os saberes dos professores da EJA. Mas quais seriam os saberes mais determinantes e específicos presentes no contexto da EJA de Florianópolis? Para poder afirmar algo mais coerente, convém partir da fala do entrevistado, o professor Pablo:

Na escola do 'ensino regular', se um aluno não está querendo te deixar dares aula, tu vais mandar ele para sala da diretora, vai ter mais gente. Agora, no nosso Núcleo, às vezes, estamos só entre professores, não tem para onde mandar, tu não podes mandar um aluno pra rua se ele é menor de idade. Tu não podes mandar para a sala da coordenadora se ela, às vezes, está na outra escola do Núcleo. Temos uma professora remanejada que trabalha na secretaria que está com um atestado bem longo, e às vezes estamos só entre professores na escola e a gente tem de lidar com essas situações de alunos que não querem entrar, alunos que entram mas querem bagunçar. (Prof. Pablo, entrevista, 2016, p. 6).

Essa fala contêm informações sobre os desafios da ação docente na EJA de Florianópolis, as situações e condicionantes cotidianas e inerentes aos trabalhos específicos desse contexto. Tais situações podem ser compreendidas a partir de uma maior autonomia docente, que leva a situações em que lidar com imprevistos é fundamental. Essa lida com o imprevisto, aqui tratada, não deve ser confundida com um desleixo, ou mesmo uma justificativa para pensar e perceber a EJA de Florianópolis num fazer espontaneísta, algo que não prevê uma preparação didático/pedagógica. Ela faz parte de todo um aparato de modos de ação docente e nunca é totalmente desvinculada de processos pedagógicos, ou seja, de uma teoria de ensino- aprendizagem. (TARDIF, 2010).

Num primeiro momento essa autonomia, que leva a situações de improviso, pode parecer algo positivo, um modo de fazer independente, uma forma de tomar decisões sem ter de passar por um crivo superior imediato. Porém, os professores não estão habituados a lidar com todas as situações inerentes a esse ambiente de ensino. Em outros contextos existe toda uma gama de profissionais responsáveis pelas tarefas escolares, existe um corpo administrativo nas instituições escolares formado por muito mais profissionais do que os encontrados nos núcleos da EJA 
que, de forma geral, contam com: um coordenador, uma professora auxiliar e nove professores (um de primeiro segmento e oito de segundo segmento). ${ }^{7} \mathrm{Na}$ fala anterior do professor Pablo é possível visualizar uma situação comum no dia-a-dia da EJA, somente os professores lidando com as mais variadas situações com os estudantes.

A princípio, considerando o amálgama, mais ou menos coerentes, de saberes disciplinares, curriculares e experienciais, apresentado por Tardif (2010), como sendo os formadores dos saberes docentes, é possível afirmar que existe um peso maior na constituição dos saberes docentes da EJA de Florianópolis ligado à experiência, à empiria de ser professor nesse contexto.

Para sustentar mais essa ideia, outra fala do professor Pablo pode contribuir: "Tem uma autonomia muito grande, e são as diversas tarefas que um professor da EJA tem que exercer. (...) Então, é professor, é inspetor, é limpeza, é serviço social, é tudo, o professor da EJA é a escola inteira." (Prof. Pablo, entrevista, 2016, p. 5). Esse relato corrobora em dois sentidos para pensarmos a especificidade da ação docente na EJA: 1) mostra o lado multifacetado da atuação docente e 2) apresenta a autonomia (imprevisibilidade) e a importância do grupo de professores como sustentáculos dessa ambiente de ensino.

As diversas formas de ação docente na EJA de Florianópolis resultam na necessidade de novas maneiras de pensar, ser e estar professor. Os indícios dessas formas de atuação docente levam a problematizar as estratégias docentes, o esforço cognitivo de lidar, muitas vezes, com situações inéditas em suas carreiras.

Para Tardif (2010, p. 49. Grifo do autor):

No exercício cotidiano de sua função, os condicionantes aparecem relacionados a situações concretas que não são passíveis de definições acabadas e que exigem improvisação e habilidade pessoal, bem como a capacidade de enfrentar situações mais ou menos transitórias e variáveis. Ora, lidar com condicionantes e situações é formador: somente isso permite ao docente desenvolver os habitus (isto é, certas disposições adquiridas na e pela prática real), que lhe permitirão justamente enfrentar os condicionantes e imponderáveis da profissão.

\footnotetext{
${ }^{7}$ O primeiro segmento corresponde aos anos iniciais do Ensino Fundamental (alfabetização e letramento) e conta com uma professora pedagoga. O segundo segmento faz referência aos anos finais do Ensino Fundamental e conta com professores de Artes (Plásticas ou Cênicas), Ciências, Educação Física, Espanhol, Geografia, História, Matemática e Português.
} 
Essa afirmação está relacionada a contextos de escolas muito diferentes da EJA de Florianópolis, pois, as pesquisas de Tardif (2010) estão concentradas principalmente no Canadá e nos Estados Unidos. Ou seja, essas situações e condicionantes do cotidiano da função docente, devem ser diferentes das enfrentadas na EJA. A grande colaboração dessa citação para este trabalho está centrada na afirmação de que enfrentar situações e condicionantes no dia a dia de sala de aula é formador. Se isso é uma verdade em outras situações de ensino, no modelo disciplinar da organização do ensino, ou seja, fora do contexto da EJA, o que dizer dentro dessa proposta da PPE, com todas as mudanças e especificidades inerentes a isso?

Para avançar e ampliar as discussões que relacionam a experiência dos professores da EJA com saberes docentes, mais uma fala do professor Pablo é pertinente:

O que mais tem marcado, para mim, é a importância da relação entre professor e aluno. Na EJA, se não tiveres um bom relacionamento com os alunos, eles não vão te deixar dares aula. Então, tu teres uma relação próxima, e até de amizade mesmo com eles, isso é o mais importante na EJA. Eles não vão deixar dares aula se eles não quiserem que tu dês aula. (Prof. Pablo, entrevista, 2016, p. 5).

A cultura escolar da EJA, ou seja, todas as nuances das práticas, hábitos e rituais proporcionadas pela PPE, que proporciona um maior contato, uma maior proximidade com os estudantes, deixa evidente essa situação/condicionante apontada pelo professor entrevistado, isso quer dizer, a importância da relação professor/aluno. Isso não é nenhuma novidade, porém, o diferencial do encontrado na EJA se refere justamente as possibilidades de ampliar e intensificar essa relação, pois o professor além de ser um parceiro nos trabalhos com as pesquisas é também um aliado em outras diversas tarefas. Chega ao ponto de o professor entrevistado falar em amizade. Mas, poderia isso atrapalhar os processos de ensino/aprendizagem? Ou ser uma forma de ir contra certa formalidade que se tenta dar a profissão docente? Aparentemente, a resposta é não, pois, para Tardif (2010, p.118. Grifo meu):

Ao entrar em sala de aula, o professor penetra em um ambiente de trabalho constituído de interações humanas. As interações com os alunos não representam, portanto, um aspecto secundário ou 
periférico do trabalho dos professores: elas constituem o núcleo e, por essa razão, determinam, ao nosso ver, a própria natureza dos procedimentos e, portanto, da pedagogia.

Tardif (2010, p. 130) diz ainda que: "Uma boa parte do trabalho docente é de cunho afetivo, emocional. Baseia-se em emoções, em afetos, na capacidade não somente de pensar nos alunos, mas igualmente de perceber e de sentir suas emoções, seus temores, suas alegrias, seus próprios bloqueios afetivos."

Seria impossível alcançar esse nível de percepção, em que é possível sentir as emoções dos estudantes, sem uma maior proximidade, numa relação tão formal e distante. Os resultados disso podem ser vistos não apenas nos estudantes, mas também nos professores, mais especificamente, na sua prática docente. Esse fator acaba sendo primordial para pensarmos seus aprendizados enquanto docente na EJA e também para além da proposta.

Tardif (2010, p. 181) afirma que:

A prática é como um processo de aprendizagem através do qual os professores e professoras retraduzem sua formação anterior e a adaptam à profissão, eliminando o que lhes parece inutilmente abstrato ou sem relação com a realidade vivida e conservando o que pode servir-lhes, de uma maneira ou de outra, para resolver os problemas da prática educativa.

Isso que é conservado de suas formações anteriores pode ser levado para contextos além da EJA, talvez, possam marcar sua trajetória profissional e possibilitar 0 ensejo de novas práticas docentes, suscitadas pelos saberes adquiridos na sua experiência na EJA de Florianópolis.

A prática profissional não é vista, assim, como simples campo de aplicação de teorias elaboradas fora dela, por exemplo nos centros de pesquisa ou nos laboratórios. Ela torna-se um espaço original e relativamente autônomo de aprendizagem e de formação para os futuros práticos, bem como um espaço de produção de saberes e de práticas inovadoras pelos professores experientes. (TARDIF, 2010, p. 286).

Essa afirmação pensada no contexto da EJA vai além do imaginado por Tardif. A empiria docente encontrada na EJA de Florianópolis possibilita uma aprendizagem talvez rara em nossos sistemas educativos. Porém, transpor a mera experiência e realmente inculcar um saber ligado à prática, depende muito da 
maneira que o próprio docente irá encarar essa prática. É possível dizer que a possibilidade de aprendizagem e de formação está caracterizada, porém, o modo como isso será assimilado é, no momento atualmente da pesquisa, difícil de ser mensurado.

\section{CONSIDERAÇÕES FINAIS}

Neste trabalho, a Pesquisa como Princípio Educativo (PPE) foi apenas uma menção, sem maiores considerações. A cultura escolar da EJA de Florianópolis foi apenas "pincelada" em aspectos mais evidentes. E os saberes docentes foram trabalhados apenas sobre os vieses da relação entre aluno e professor e da aprendizagem pela prática, sem levantar questões sobre currículo da EJA, sobre a formação anterior dos professores e nem sobre as demais formas de materialização de saberes docentes ligados diretamente à ação dos profissionais professores.

Porém, mesmo com essas limitações, as falas do professor Pablo e a bibliografia consultada auxiliaram em algumas conclusões que parecem pertinentes. Uma delas seria a especificidade da cultura escolar vivenciada pelos sujeitos da EJA. É evidente que a PPE da EJA de Florianópolis apresenta um conjunto de normas, condutas, práticas e espaços peculiares.

É possível afirmar também que essa cultura escolar específica possibilita diferentes formas de ação docente em sala de aula, desenvolvendo e mobilizando saberes e conhecimentos práticos/teóricos também específicos. Essa ação, a partir dessa prática com pesquisas, da autonomia e imprevisibilidade, da relação mais próxima com os estudantes e da relação com todo o grupo de profissionais envolvidos nos núcleos, possibilita um tipo de formação mediada pela lida cotidiana com situações e condicionantes impostas em seu ambiente de trabalho. Essa situação, entendida como de formação, configura e mobiliza saberes específicos ligados a essa prática peculiar, nesse ambiente de ensino distinto.

\section{REFERÊNCIAS}


FARIA FILHO, Luciano Mendes de; VIDAL, D.G.; PAULILO, L. P. A cultura escolar como categoria de análise e como campo de investigação na história da educação brasileira. Revista Educação e Pesquisa. São Paulo, v.30, no1, jan/abr, 2004, p. 139-159.

JULIA, Dominique. A Cultura escolar como Objeto Histórico. Revista brasileira de história da educação. no 1, jan/jun, 2001. p. 09-43.

OLIVEIRA, Gilvan Müller (org.). Interesse, Pesquisa e Ensino: uma equação para a educação escolar no Brasil. Florianópolis: Prelo, 2004.

PORTELLI, Alessandro. A filosofia e os fatos: narração, interpretação e significados nas memórias a nas fontes orais. Tempo. Rio de Janeiro, v.1, n.2, 1996, p. 59-72

. O que faz a história oral diferente. Projeto História. São Paulo, n.14, fev./1997a, p. 25-39.

. Tentando aprender um pouquinho: algumas reflexões sobre a ética na história oral. Projeto História. São Paulo, n.15. abr./1997b, p. 13-49.

"AUTOR". Saberes Docentes na Educação de Jovens e Adultos em Florianópolis (SC). 2017. Dissertação (Mestrado em Educação). Universidade Federal de Santa Catarina. Florianópolis.

TARDIF, Maurice. Saberes docentes e formação profissional. Petrópolis: Vozes, 2010.

Saberes profissionais dos professores e conhecimentos universitários: elementos para uma epistemologia da prática profissional dos professores e suas consequências em relação à formação para o magistério. Revista Brasileira de Educação. ำ 13, 2000. p. 5-24.

A profissionalização do ensino passados trinta anos: dois passos para frente, três para trás. Educação \& Sociedade. Campinas, v.34, n. 123, abr.-jun. 2013. p. 551-571.

VIÑAO FRAGO, Antonio. Sistemas educativos, culturas ecolares y reformas. Madrid: Morata, 2006. 